\title{
Isolation, purification and identification of biological compounds from Beauveria sp. and their evaluation as insecticidal effectiveness against Bemisia tabaci
}

\author{
Ran An ( $\square$ anan8u8@outlook.com ) \\ Shenyang Agricultural University \\ Maqsood Ahmed \\ Shenyang Agricultural University \\ Haiyan Li \\ Shenyang Agricultural University \\ Yanbin Wang \\ Shenyang Agricultural University \\ Aimin Zhang \\ Shenyang Agricultural University \\ Yuhui Bi \\ Shenyang Agricultural University \\ ZhiguoYu ( $\square$ zyu@syau.edu.cn ) \\ Shenyang Agricultural University
}

\section{Research Article}

Keywords: Beauveria sp., MEAM1, insecticidal activity, cerebrosides, sterols

Posted Date: March 22nd, 2021

DOI: https://doi.org/10.21203/rs.3.rs-347469/v1

License: (9) (i) This work is licensed under a Creative Commons Attribution 4.0 International License. Read Full License 


\section{Abstract}

Bemisia tabaci is one of the most notorious agricultural pests in the world. A vicious circle among insect resistance, dose increased, environment and human body impaired as the overuse of synthetic pesticides are becoming increasingly evident. Entomopathogenic Beauveria sp. is known as an effective natural enemy to control $B$. tabaci. Therefore, this study aimed to purify and identify the biological compounds from Beauveria sp. LY2 via extensive chromatographic techniques, NMR and MS and evaluated for their insecticidal activities against $B$. tabaci via contact and stomach toxicity assay. The outcome identified that one new cerebroside, cerebroside $F(\mathbf{1})$, nine known compounds, cerebroside $B(2)$, bassiatin (3), methyl 1,4-dihydro-4-oxo-2-quinolinecarboxylate (4), cerevisterol (5), 9-hydroxycerevisterol (6), 6-

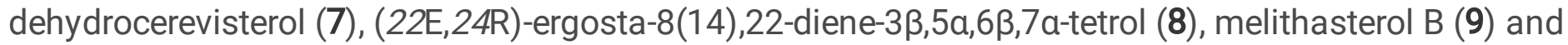
ergosterol peroxide (10) were isolated. Among the known compounds, methyl 1,4-dihydro-4-oxo- 2quinolinecarboxylate (4) was isolated from natural origin for the first time. It is evident from the results that compounds $3, \mathbf{4}$ and $\mathbf{7}$ strongly featured insecticidal activities against $B$. tabaci, being the $\mathrm{LC}_{50}$ value as $10.59,19.05,26.59 \mu \mathrm{g} / \mathrm{mL}$ respectively in contact as well as $11.42,5.66,5.65 \mu \mathrm{g} / \mathrm{mL}$ respectively in stomach experiment. The data from the current study has provided the foundation for the use of newly purified compounds against Bemisia tabacias an alternative to synthetic chemical compounds.

\section{Introduction}

The whitefly, Bemisia tabaci (Hemiptera: Aleyrodidae) is one of the world's top 100 invasive species which can attack more than 600 agricultural plant-host species under field and greenhouse conditions ${ }^{1,2}$. Due to its piercing-sucking mouthpart, $B$. tabaci can directly cause plant weakness and indirectly transmit approximately 111 plant viruses ${ }^{3}$. Both nymphs and adults can also secrete honeydew, which can induce coal pollution. Besides B biotype (MEAM1) is the dominant species which significantly threatened many agricultural commodities in numerous countries ${ }^{4-6}$. Moreover, for the excessive use of synthetic pesticides have contributed to resistance development of $B$. tabaci. So far, 64 active ingredients have been reported for resistance from $B$. tabaci ${ }^{7}$.

The injudicious and excessive use of broad-spectrum synthetic pesticide can do harm to human health and environment ${ }^{8}$, and it can also result in the development of heritable resistance, pest resurgence and secondary pest problems. By contrast, bio-insecticides are safer for humans and more environmentally friendly. Moreover, plant and fungi are the sources of thousands of secondary metabolites ${ }^{9}$. Those secondary metabolites are ideal substitutes of those chemicals which play a significant role and possess a great potential on the field of biopesticides ${ }^{10}$.

Beauveria sp. (Ascomycota: Hypocreales) is a facultative entomopathogen with an extremely broad spectrum which is used as a commercial biopesticide against many agriculturally important insect pests

11. The metabolites from Beauveria sp. can be divided into three main kinds, such as alkaloids (tenellin, bassiatin, pyridovercin, pyridomacrolidin, ilicicdin H), cyclodepsipetides (beauvericins, allobeauvericins, 
bassianolides, beauveriolides) and benzoquinone (oosporein), many of them exert insecticidal ${ }^{12,13}$, anthelminthic ${ }^{14}$, synergistic antifungal ${ }^{15}$, antibacterial ${ }^{16,17}$, antiviral ${ }^{18}$ and cytotoxic activities ${ }^{19}$. However, research on the secondary metabolites of Beauveria sp. has a history of nearly 60 years, but the research on its activity is mainly focused on the field of medicinal use, and there are very few activities in the field of agriculture, in particular insecticidal activity. Although some studies have been conducted in isolation and identification of various compounds from natural resources, but, there is no research of bassiatin in the agricultural field per se. Therefore, this research study not only supplements the gap in the insecticidal activity of bassiatin, but also adds two types of substances to the group of secondary metabolites of Beauveria sp., and evaluates their insecticidal effects in both stomach and contact toxicity effects.

\section{Results}

\subsection{Extraction, Separation and Purification of Extract}

After silica gel column chromatography, gel chromatography and HPLC, compounds 1-10 were obtained. Among them, compound $\mathbf{1}$ is a new cerebroside compound, $\mathbf{4}$ is a new natural product, and 2-10 are all confirmed to be known compounds after comparison with previous studies, they are cerebroside B (2) ${ }^{20}$, bassiatin (3) ${ }^{21}$, methyl 1,4-dihydro-4-oxo-2-quinolinecarboxylate (4) ${ }^{22,23}$, cerevisterol (5) ${ }^{24}, 9$ -

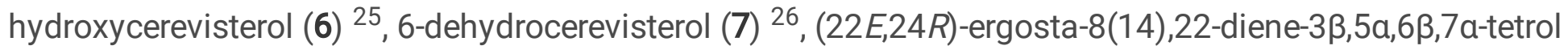
$(8)^{27}$, melithasterol B (9) ${ }^{28}$, ergosterol peroxide (10) ${ }^{28}$. Compounds $1-2,4-9$ are all isolated from Beauveria sp. for the first time. The Chemical structures of all the purified compounds (1-10) are presented in Figure 1.

\subsection{Structure Elucidation of Compounds}

Compound 1 , white amorphous powder, possessed a molecular formula of $\mathrm{C}_{41} \mathrm{H}_{75} \mathrm{NO}_{10}$ by the positive HR-ESI-MS ( $\mathrm{m} / \mathrm{z} 742.5457[\mathrm{M}+\mathrm{H}]^{+}$, calcd. 742.5469), requiring five indices of hydrogen deficiency. The ${ }^{1} \mathrm{H}$ NMR spectrum (Table 1 ) in methanol- $d_{4}$ of 1 showed two terminal olefinic protons at $\delta_{H} 5.79,6.09$ (each $1 \mathrm{H}, \mathrm{br} \mathrm{s}, \mathrm{H}-19)$, two mutually coupled trans olefinic protons at $\delta_{\mathrm{H}} 5.74(1 \mathrm{H}, \mathrm{dtd}, J=15.4,6.6,0.7 \mathrm{~Hz}, \mathrm{H}-5)$, $5.50(1 \mathrm{H}, \mathrm{ddt}, J=15.4,7.3,1.3 \mathrm{~Hz}, \mathrm{H}-4)$, the diagnostic anomeric proton of $\beta$-glucopyranoside moiety at $\delta_{H} 4.26\left(1 \mathrm{H}, \mathrm{d}, J=7.8 \mathrm{~Hz}, \mathrm{H}-1^{\prime \prime}\right)$, as well as two long-chain terminal methyl triplets at $\delta_{\mathrm{H}} 0.89(6 \mathrm{H}, \mathrm{t}, J=7.0$ $\mathrm{Hz}, \mathrm{H}-18, \mathrm{H}-16^{\prime}$ ). The ${ }^{13} \mathrm{C}$ NMR spectrum (Table 1) exhibited an a, $\beta$-unsaturated carbonyl carbon at $\delta_{\mathrm{C}}$ 203.0 (s, C-8), an amide acyl carbon at $\delta_{C} 177.2($ s, C-1'), four olefinic carbon signals, a set of characteristic carbons corresponding to a $\beta$-D-glucopyranoside moiety appeared at $\delta_{C} 104.7$ (d, C-1"), 75.0 (d, C-2"), 77.9 (d, C-3"), 71.6 (d, C-4"), 78.0 (d, C-5") and 62.7 (t, C-6"), other three oxygenated carbons at $\delta_{C} 73.0(d), 72.7(d)$ and $69.7(t)$, as well as a series of long-chain aliphatic carbon signals. The above NMR features were similar to those of cerebroside B (2) ${ }^{20}$, also isolated from the current study, and the obvious difference between them only came from the olefinic methyl part of the main chain, in which the olefinic methyl signal was disappeared and replaced by a terminal olefinic methylene in 1 , in addition, a 
keto carbonyl at $\delta_{\mathrm{C}} 203.0$ was newly detected. In the HMBC spectrum (Figure S3), the correlations from $\mathrm{H}$ $19\left[\delta_{H} 5.79,6.09\right.$ (each $1 \mathrm{H}$, br s) ] to the keto carbonyl carbon confirmed the presence of $a, \beta$-unsaturated carbonyl moiety. Furthermore, the correlations from H-7 [2.82 (2H, br t, $J=7.4 \mathrm{~Hz})]$ to $\mathrm{C}-5[133.4$ (d)] and C-8 [203.0 (s)] revealed the keto carbonyl at C-8. In view of their consistency of the chemical shifts and coupling constants, the configurations of C-2, C-3 and C-2' were deduced to be the same as those of 2 . The interpretation of the MS fragment ions (see Figure $\mathrm{S} 8$ in supplementary material) allowed to determine the specific length of the two chains. Therefore, the structure of compound 1 was established as illustrated in Figure 2 and named as cerebroside F.

Table 1. The ${ }^{1} \mathrm{H}$ NMR and ${ }^{13} \mathrm{C}$ NMR spectral data of the compound 1 in methanol-d4

\begin{tabular}{|c|c|c|c|c|c|}
\hline No. & ${ }^{1} \mathrm{H}$ NMR & ${ }^{13} \mathrm{C}$ NMR & No. & ${ }^{1} \mathrm{H}$ NMR & ${ }^{13} \mathrm{C}$ NMR \\
\hline \multirow[t]{2}{*}{1} & $3.70(1 \mathrm{H}, \mathrm{dd}, 10.4,3.6)$ & \multirow[t]{2}{*}{$69.7(\mathrm{t})$} & \multirow[t]{2}{*}{19} & \multirow{2}{*}{$\begin{array}{l}5.79,6.09(\text { each } 1 \mathrm{H}, \mathrm{br} \\
\mathrm{s})\end{array}$} & \multirow[t]{2}{*}{$125.2(t)$} \\
\hline & $4.10(1 \mathrm{H}, \mathrm{dd}, 10.4,5.6)$ & & & & \\
\hline 2 & $3.98(1 \mathrm{H}, \mathrm{m})$ & $54.6(d)$ & $1^{\prime}$ & - & $177.2(\mathrm{~s})$ \\
\hline 3 & $4.13(1 \mathrm{H}, \mathrm{br} \mathrm{dd}, 7.5,7.3)$ & 72.7 (d) & $2^{\prime}$ & $3.97(1 \mathrm{H}, \mathrm{m})$ & $73.0(d)$ \\
\hline 4 & $\begin{array}{l}5.50(1 \mathrm{H}, \mathrm{ddt}, 15.4,7.3 \\
1.3)\end{array}$ & $131.7(d)$ & $3^{\prime}$ & $\begin{array}{l}\text { 1.54, } 1.71(\text { each } 1 \mathrm{H}, \\
\mathrm{m})\end{array}$ & $35.9(\mathrm{t})$ \\
\hline 5 & $\begin{array}{l}5.74(1 \mathrm{H}, \mathrm{dtd}, 15.4,6.6 \\
0.7)\end{array}$ & $133.4(d)$ & $4^{\prime}$ & $1.35-1.45(2 \mathrm{H}, \mathrm{m})$ & $26.2(\mathrm{t})$ \\
\hline 6 & $2.26-2.33(2 \mathrm{H}, \mathrm{m})$ & $28.1(\mathrm{t})$ & $5^{\prime}-13^{\prime}$ & $1.24-1.33(18 \mathrm{H}, \mathrm{m})$ & $\begin{array}{l}30.5-30.8 \\
(\mathrm{t})\end{array}$ \\
\hline 7 & $2.82(2 \mathrm{H}, \mathrm{br} \mathrm{t}, 7.4)$ & $38.1(t)$ & $14^{\prime}$ & $1.27(2 \mathrm{H}, \mathrm{m})$ & $33.1(\mathrm{t})$ \\
\hline 8 & - & 203.0 (s) & $15^{\prime}$ & $1.30(2 \mathrm{H}, \mathrm{m})$ & $23.7(\mathrm{t})$ \\
\hline 9 & - & $150.2(\mathrm{~s})$ & $16^{\prime}$ & $0.89(3 \mathrm{H}, \mathrm{t}, 7.0)$ & $14.4(q)$ \\
\hline 10 & $2.25(2 \mathrm{H}, \mathrm{brt}, 7.6)$ & $32.0(\mathrm{t})$ & $1 "$ & $4.26(1 \mathrm{H}, \mathrm{d}, 7.8)$ & $104.7(d)$ \\
\hline 11 & $1.38(2 \mathrm{H}, \mathrm{m})$ & $29.8(t)$ & $2 "$ & $3.18(1 \mathrm{H}, \mathrm{dd}, 9.2,7.8)$ & $75.0(d)$ \\
\hline $12-15$ & $1.24-1.33(8 \mathrm{H}, \mathrm{m})$ & $\begin{array}{l}30.5-30.8 \\
(\mathrm{t})\end{array}$ & $3^{\prime \prime}$ & $3.35(1 \mathrm{H}, \mathrm{dd}, 9.2,8.8)$ & 77.9 (d) \\
\hline 16 & $1.27(2 \mathrm{H}, \mathrm{m})$ & $33.1(\mathrm{t})$ & $4 "$ & $3.27(1 \mathrm{H}, \mathrm{m})$ & $71.6(d)$ \\
\hline 17 & $1.30(2 \mathrm{H}, \mathrm{m})$ & $23.7(\mathrm{t})$ & $5^{\prime \prime}$ & $3.27(1 \mathrm{H}, \mathrm{m})$ & $78.0(d)$ \\
\hline \multirow[t]{2}{*}{18} & \multirow[t]{2}{*}{$0.89(3 \mathrm{H}, \mathrm{t}, 7.0)$} & \multirow[t]{2}{*}{$14.4(q)$} & \multirow[t]{2}{*}{$6 "$} & $3.66(1 \mathrm{H}, \mathrm{dd}, 11.9,5.5)$ & \multirow[t]{2}{*}{$62.7(\mathrm{t})$} \\
\hline & & & & $3.86(1 \mathrm{H}, \mathrm{dd}, 11.9,1.3)$ & \\
\hline
\end{tabular}


Compound 2, white amorphous powder, $\mathrm{C}_{41} \mathrm{H}_{77} \mathrm{NO}_{9}$, HR-ESI-MS (m/z $\left.728.5625[\mathrm{M}+\mathrm{H}]^{+}\right) .{ }^{1} \mathrm{H}$ NMR (s, 600 MHz, DMSO) $\delta 7.39$ (d, $J=9.3 \mathrm{~Hz}, 1 \mathrm{H}, \mathrm{NH}), 5.59(\mathrm{~m}, 1 \mathrm{H}, \mathrm{H}-5), 5.50\left(\mathrm{~d}, J=5.2 \mathrm{~Hz}, 1 \mathrm{H}, \mathrm{OH}-2^{\prime}\right), 5.40$ (dd, $J=$ 15.4, $6.8 \mathrm{~Hz}, 1 \mathrm{H}, \mathrm{H}-4), 5.09$ (d, J = $6.6 \mathrm{~Hz}, 1 \mathrm{H}, \mathrm{H}-8), 4.96(\mathrm{~d}, J=4.1 \mathrm{~Hz}, 1 \mathrm{H}, \mathrm{OH}-3), 4.93(\mathrm{~d}, J=5.5 \mathrm{~Hz}, 1 \mathrm{H}$, $\left.\mathrm{OH}-3^{\prime \prime}\right), 4.90$ (dd, $\left.J=7.9,5.0 \mathrm{~Hz}, 2 \mathrm{H}, \mathrm{OH}-2^{\prime \prime}, \mathrm{OH}-4^{\prime \prime}\right), 4.51$ (t, $\left.J=5.9 \mathrm{~Hz}, 1 \mathrm{H}, \mathrm{OH}-6 "\right), 4.12(\mathrm{~d}, J=7.8 \mathrm{~Hz}, 1 \mathrm{H}, \mathrm{H}-$ 1"), 3.99 (dd, $J=12.9,6.6 \mathrm{~Hz}, 1 \mathrm{H}, \mathrm{H}-1), 3.92$ (dd, $J=10.4,5.8 \mathrm{~Hz}, 1 \mathrm{H}, \mathrm{H}-3), 3.81\left(\mathrm{~m}, 2 \mathrm{H}, \mathrm{H}-2, \mathrm{H}-2^{\prime}\right), 3.66$ (dd, $\left.J=10.0,6.1 \mathrm{~Hz}, 1 \mathrm{H}, \mathrm{H}-6^{\prime \prime}\right), 3.52(\mathrm{dd}, J=10.3,3.7 \mathrm{~Hz}, 1 \mathrm{H}, \mathrm{H}-1), 3.43\left(\mathrm{dt}, J=11.7,5.9 \mathrm{~Hz}, 1 \mathrm{H}, \mathrm{H}-6^{\prime \prime}\right), 3.13(\mathrm{td}$, $\left.J=8.8,4.8 \mathrm{~Hz}, 1 \mathrm{H}, \mathrm{H}-3^{\prime \prime}\right), 3.08$ (d, $\left.J=5.8 \mathrm{~Hz}, 1 \mathrm{H}, \mathrm{H}-5^{\prime \prime}\right), 3.04$ (dd, $\left.J=8.8,5.2 \mathrm{~Hz}, \mathrm{H}, \mathrm{H}-4^{\prime \prime}\right), 2.95$ (td, $J=8.4$, $\left.4.2 \mathrm{~Hz}, 1 \mathrm{H}, \mathrm{H}-2^{\prime \prime}\right), 1.98(\mathrm{~m}, 4 \mathrm{H}, \mathrm{H}-6, \mathrm{H}-7), 1.92$ (t, J = 7.5 Hz, 2H, H-10), 1.55 (d, J = 14.5 Hz, 3H, Me-9), 1.47 - 1.14 (overlap, $\mathrm{m}, 4 \mathrm{OH}, \mathrm{CH}_{2}-11 \sim 17, \mathrm{CH}_{2}-3^{\prime} \sim 15^{\prime}$ ) , 0.86 (s, m, 6H, Me-18, Me-16'). ${ }^{13} \mathrm{C}$ NMR $(151 \mathrm{MHz}$, DMSO) $\delta 174.14$ (C-1'), 135.26 (C-9), 131.47 (C-5), 131.39 (C-4), 123.86 (C-8), 103.89 (C-1"), 77.28 (C-5"), 76.93 (C-3"), 73.78 (C-2"), 71.41 (C-2'), 70.93 (C-1), 70.39 (C-4"), 69.11 (C-3), 61.44 (C-6"), 53.22 (C-2), 39.43 (C-10) 34.86 (C-3'), 32.54 (C-6), $31.69-29.07$ (overlap, C-12 16, C-5' 14'), 27.75 (C-7), 27.62 (C11), 24.92 (C-4'), 22.49 (C-15'), 16.09 (C-19), 14.31 (overlap, C-18, C-16').

Compound 3, colorless crystal, $\mathrm{C}_{15} \mathrm{H}_{19} \mathrm{NO}_{3}$, ESI-MS (m/z $\left.261.00[\mathrm{M}]^{+}\right)^{1} \mathrm{H}$ NMR $\left(600 \mathrm{MHz}, \mathrm{CDCl}_{3}\right) \delta 7.33$ (overlap, m, 3H, H-13,H-14,H-15), 7.13 (overlap, m, 2H, H-12, H-16), 4.41 (t, J=4.4 Hz, 1H, H-3), 3.24 (dd, J = 37.0, 4.4 Hz, 1H, H-10), 3.03 (s, 3H, N- Me), 3.01 (d, J = 2.2 Hz, 1H, H-6), 2.30 (hd, J = 6.9, 2.2 Hz, 1H, H-7), 0.85 (d, $J=7.1 \mathrm{~Hz}, 3 \mathrm{H}, \mathrm{Me}-8), 0.77$ (d, $J=6.8 \mathrm{~Hz}, 3 \mathrm{H}, \mathrm{Me}-9) .{ }^{13} \mathrm{C} \mathrm{NMR}\left(151 \mathrm{MHz}, \mathrm{CDCl}_{3}\right) \delta 167.38$ (s, C-2), 165.64 (s, C-5), 134.26 (s, C-11), 129.89 (overlap, s, C-12, C-16), 129.34 (overlap, s, C-13, C-15), 128.33 (s, C-14), 81.38 (s, C-6), 62.87 (s, C-3), 37.19 (s, C-10), 32.53 (s, N- Me), 29.77 (s, C-7), 18.68 (s, C-8), 15.24 (s, C-9).

Compound 4 is white amorphous powder, $\mathrm{C}_{11} \mathrm{H}_{9} \mathrm{NO}_{3}$, ESI-MS (m/z $\left.202.20[\mathrm{M}-\mathrm{H}]-{ }^{-}\right) .{ }^{1} \mathrm{H}$ NMR $(600 \mathrm{MHz}$, $\mathrm{CDCl}_{3}$ ) ठ $9.26(\mathrm{~s}, 1 \mathrm{H}, \mathrm{H}-\mathrm{N}), 8.36(\mathrm{~d}, J=8.1 \mathrm{~Hz}, 1 \mathrm{H}, \mathrm{H}-5), 7.67(\mathrm{t}, J=7.7 \mathrm{~Hz}, 1 \mathrm{H}, \mathrm{H}-7), 7.48(\mathrm{~d}, J=8.3 \mathrm{~Hz}, 1 \mathrm{H}$, $\mathrm{H}-8), 7.39(\mathrm{t}, J=7.6 \mathrm{~Hz}, 1 \mathrm{H}, \mathrm{H}-6), 6.99(\mathrm{~s}, 1 \mathrm{H}, \mathrm{H}-3), 4.04(\mathrm{~s}, 3 \mathrm{H}, \mathrm{H}-10) .{ }^{13} \mathrm{C} \mathrm{NMR}\left(151 \mathrm{MHz}, \mathrm{CDCl}_{3}\right) \delta 179.55$ (C-4), 163.40 (C-9), 138.96 (C-1a), 136.10 (C-2), 133.10 (C-7), 126.34 (C-4a), 126.27 (C-5), 124.51 (C-6), 117.97 (C-8), 111.65 (C-3), 53.76 (C-10).

Compound 5, white amorphous powder, $\mathrm{C}_{28} \mathrm{H}_{46} \mathrm{O}_{3}$, ESI-MS (m/z $\left.431.20[\mathrm{M}+\mathrm{H}]^{+}\right) .{ }^{1} \mathrm{H} \mathrm{NMR}(600 \mathrm{MHz}$, $\mathrm{CDCl}_{3}$ ) $\delta 5.36(\mathrm{~m}, 1 \mathrm{H}, \mathrm{H}-7), 5.23$ (dd, $\left.J=15.3,7.5 \mathrm{~Hz}, 1 \mathrm{H}, \mathrm{H}-23\right), 5.16$ (dd, $\left.J=15.3,8.2 \mathrm{~Hz}, 1 \mathrm{H}, \mathrm{H}-22\right), 4.08$ (td, $J=11.3,5.7 \mathrm{~Hz}, 1 \mathrm{H}, \mathrm{H}-3), 3.62(\mathrm{~d}, J=5.0 \mathrm{~Hz}, 1 \mathrm{H}, \mathrm{H}-6), 1.09$ (s, 3H, Me-19), $1.03(\mathrm{~d}, J=6.6 \mathrm{~Hz}, 3 \mathrm{H}, \mathrm{Me}-$ 21), $0.92(\mathrm{~d}, J=6.8 \mathrm{~Hz}, 3 \mathrm{H}, \mathrm{Me}-28), 0.83(\mathrm{dd}, J=9.3,6.8 \mathrm{~Hz}, 6 \mathrm{H} \mathrm{Me}-26, \mathrm{Me}-27), 0.60$ (s, 3H, Me-18). ${ }^{13} \mathrm{C}$ NMR (151 MHz, CDCl ${ }_{3}$ ) $\delta 144.03$ (C-8), 135.39 (C-22), 132.20 (C-23), 117.56 (C-7), 75.98 (C-5), 73.69 (C-6), 67.74 (C-3), 56.01 (C-17), 54.77 (C-14), 43.78 (C-13), 43.49 (C-9), 42.83 (C-24), 40.40 (C-20), 39.49 (C-4), 39.24 (C-12), 37.16 (C-20), 33.09 (C-25), 32.98 (C-1), 30.88 (C-2), 27.91 (C-16), 22.90 (C-15), 22.06 (C-11), 21.13 (C-21), 19.96 (C-26), 19.65 (C-27), 18.85 (C-19), 17.60 (C-28), 12.34 (C-18).

Compound 6, white amorphous powder, $\mathrm{C}_{28} \mathrm{H}_{46} \mathrm{O}_{4}, \mathrm{HR}$-ESI-MS (m/z $\left.915.6686[2 \mathrm{M}+\mathrm{Na}]^{+}\right) .{ }^{1} \mathrm{H}$ NMR $(600$ $\mathrm{MHz}, \mathrm{MeOD}) \delta 5.36(\mathrm{dd}, J=5.2,2.3 \mathrm{~Hz}, 1 \mathrm{H}, \mathrm{H}-7), 5.26(\mathrm{~m}, 2 \mathrm{H}, \mathrm{H}-22, \mathrm{H}-23), 4.03(\mathrm{~m}, 1 \mathrm{H}, \mathrm{H}-3), 3.68$ (dd, $J=$ 5.2, $2.5 \mathrm{~Hz}, 1 \mathrm{H}, \mathrm{H}-6), 2.53$ (m, 1H, H-14), 1.15 (s, 3H, Me-19), 1.07 (t, J = 6.2 Hz, 3H, Me-21), 0.98 (t, J = 7.2 
$\mathrm{Hz}, 3 \mathrm{H}, \mathrm{Me}-28), 0.89$ (dd, $J=11.6,6.8 \mathrm{~Hz}, 6 \mathrm{H}, \mathrm{Me}-26, \mathrm{Me}-27), 0.69$ (s, 3H, Me-18). ${ }^{13} \mathrm{C}$ NMR $(151 \mathrm{MHz}$, MeOD) $\delta 144.65$ (C-8), 137.84 (C-22), 134.17 (C-23), 121.89 (C-7), 79.77 (C-5), 76.95 (C-9), 74.57 (C-6), 69.03 (C-3), 58.24 (C-17), 52.74 (C-14), 45.68 (C-13), 45.22 (C-24), 42.70 (C-20), 42.28 (C-10), 41.61 (C-4), 37.39 (C-12), 35.24 (C-25), 32.50 (C-2), 30.06 (C-11), 30.03(C-16), 29.12 (C-1), 24.87 (C-15), 23.09 (C-19), 22.50 (C-21), 21.33 (C-26), 20.95 (C-27), 19.07 (C-28), 13.13 (C-18).

Compound 7, white amorphous powder, $\mathrm{C}_{28} \mathrm{H}_{44} \mathrm{O}_{3}$, ESI-MS (m/z $\left.429.20[\mathrm{M}+\mathrm{H}]^{+}\right) .{ }^{1} \mathrm{H} \mathrm{NMR}(600 \mathrm{MHz}$, $\mathrm{CDCl}_{3}$ ) $\delta 5.65(\mathrm{~s}, 1 \mathrm{H}, \mathrm{H}-7), 5.24$ (dd, $\left.J=15.3,7.7 \mathrm{~Hz}, 1 \mathrm{H}, \mathrm{H}-23\right), 5.16$ (dd, $\left.J=15.3,8.4 \mathrm{~Hz}, 1 \mathrm{H}, \mathrm{H}-22\right), 4.03$ $(\mathrm{m}, 1 \mathrm{H}, \mathrm{H}-3), 2.52(\mathrm{~m}, 1 \mathrm{H}, \mathrm{H}-13), 1.04(\mathrm{~d}, J=6.6 \mathrm{~Hz}, 3 \mathrm{H}, \mathrm{Me}-21), 0.96(\mathrm{~d}, J=5.8 \mathrm{~Hz}, 3 \mathrm{H}, \mathrm{Me}-19), 0.92$ (d, $J=$ $6.8 \mathrm{~Hz}, 3 \mathrm{H}, \mathrm{Me}-28), 0.83$ (dd, $J=9.6,6.8 \mathrm{~Hz}, 6 \mathrm{H}, \mathrm{Me}-27, \mathrm{Me}-26), 0.61$ (s, 3H, Me-18). ${ }^{13} \mathrm{C} \mathrm{NMR}(151 \mathrm{MHz}$, $\mathrm{CDCl}_{3}$ ) $\delta 198.31$ (C-6), 165.32 (C-8), 135.02 (C-22), 132.51 (C-23), 119.71 (C-7), 77.81 (C-5), 67.50 (C-3), 56.05 (C-17), 55.82 (C-14), 44.78 (C-9), 43.90 (C-13), 42.82 (C-24), 40.46 (C-20), 40.28 (C-12), 38.85 (C-4), 36.51 (C-10), 33.06 (C-25), 30.37 (C-2), 30.23 (C-1), 29.71 (C-16), 27.86 (C-16), 22.49 (C-11), 21.96 (C-15), 21.11 (C-21), 19.95 (C-26), 19.65 (C-27), 17.58 (C-19), 16.43 (C-28), 12.70 (C-18).

Compound 8, white amorphous powder, $\mathrm{C}_{28} \mathrm{H}_{46} \mathrm{O}_{4}$, ESI-MS $\left(\mathrm{m} / \mathrm{z} 447.10[\mathrm{M}+\mathrm{H}]^{+}\right) .{ }^{1} \mathrm{H}$ NMR $(600 \mathrm{MHz}$, $\mathrm{CDCl}_{3}$ ) $\delta 5.20$ (qd, $\left.J=15.3,7.3 \mathrm{~Hz}, 2 \mathrm{H}, \mathrm{H}-22, \mathrm{H}-23\right), 4.42(\mathrm{~s}, 1 \mathrm{H}, \mathrm{H}-6), 3.91(\mathrm{~m}, 1 \mathrm{H}, \mathrm{H}-3), 3.14(\mathrm{~d}, J=3.5 \mathrm{~Hz}$, $1 \mathrm{H}, \mathrm{H}-7), 2.61$ (dt, $J=17.0,8.4 \mathrm{~Hz}, 1 \mathrm{H}, \mathrm{H}-15), 1.02(\mathrm{~d}, J=6.7 \mathrm{~Hz}, 3 \mathrm{H}, \mathrm{Me}-21), 0.91(\mathrm{t}, J=7.3 \mathrm{~Hz}, 3 \mathrm{H}, \mathrm{Me}-25)$, 0.87 (m, 6H, Me-18, Me-19), 0.83 (dd, $J=9.9,6.8 \mathrm{~Hz}, 6 \mathrm{H}, \mathrm{Me}-27, \mathrm{Me}-28) .{ }^{13} \mathrm{C} \mathrm{NMR}\left(\mathrm{s}, 151 \mathrm{MHz}, \mathrm{CDCl}_{3}\right.$ ) 8152.62 (C-14), 135.27 (C-22), 132.26 (C-23), 125.19 (C-8), 68.69 (C-3), 67.80 (C-5), 65.08 (C-6), 61.35 (C7), 56.83 (C-17), 42.98 (C-24), 42.85 (C-13), 39.58 (C-20), 39.25 (C-3), 38.74 (C-9), 36.60 (C-12), 35.85 (C10), 33.10 (C-26), 32.20 (C-1), 31.11 (C-2), 27.18 (C-16), 24.96 (C-15), 21.24 (C-21), 19.97 (C-28), 19.67 (C27), 19.00 (C-11), 18.07 (C-19), 17.62 (C-18), 16.53 (C-25).

Compound 9, white amorphous powder, $\mathrm{C}_{28} \mathrm{H}_{44} \mathrm{O}_{3}$, ESI-MS (m/z $\left.451.30[\mathrm{M}+\mathrm{Na}]^{+}\right) .{ }^{1} \mathrm{H}$ NMR $(600 \mathrm{MHz}$, $\mathrm{CDCl}_{3}$ ) $\delta 5.19(\mathrm{dq}, J=15.3,7.7 \mathrm{~Hz}, 2 \mathrm{H}, \mathrm{H}-22, \mathrm{H}-23), 4.22(\mathrm{~s}, 1 \mathrm{H}, \mathrm{H}-7), 3.95(\mathrm{~m}, 1 \mathrm{H}, \mathrm{H}-3), 3.31$ (d, J= 2.6 Hz, $1 \mathrm{H}, \mathrm{H}-6), 1.14$ (s, 1H, H-19), 1.02 (d, $J=6.6 \mathrm{~Hz}, 3 \mathrm{H}, \mathrm{Me}-21), 0.91$ (d, $J=6.8 \mathrm{~Hz}, 3 \mathrm{H}, \mathrm{Me}-28), 0.83$ (dd, $J=$ 9.5, 6.8 Hz, 6H, Me-26, Me-27), 0.59 (s, 3H, Me-18). ${ }^{13} \mathrm{C} \mathrm{NMR} \mathrm{(s,} 151 \mathrm{MHz}, \mathrm{CDCl}_{3}$ ) $\delta 135.56$ (C-22), 134.47 (C-9), 132.01 (C-23), 126.94 (C-8), 68.57 (C-3), 67.12 (C-7), 65.66 (C-5), 62.62 (C-6), 49.60 (C-14), 42.84 (C24), 42.09 (C-13), 40.41 (C-20), 39.16 (C-4), 38.00 (C-10), 35.68 (C-12), 33.10(C-25), 30.84 (C-2), 30.20 (C1), 29.01 (C-16), 23.85 (C-15), 23.4 1(C-11), 22.81 (C-19), 20.96 (C-21), 19.97 (C-27), 19.65 (C-26), 17.66 (C-28), 11.29 (C-18).

Compound 10, white amorphous powder, $\mathrm{C}_{28} \mathrm{H}_{44} \mathrm{O}_{3}$, ESI-MS (m/z $\left.429.20[\mathrm{M}+\mathrm{H}]^{+}\right) .{ }^{1} \mathrm{H}$ NMR $(600 \mathrm{MHz}$, $\left.\mathrm{CDCl}_{3}\right) \delta 6.50(\mathrm{~d}, J=8.5 \mathrm{~Hz}, 1 \mathrm{H}, \mathrm{H}-7), 6.24(\mathrm{~d}, J=8.5 \mathrm{~Hz}, 1 \mathrm{H}, \mathrm{H}-6), 5.22(\mathrm{dd}, J=15.2,7.7 \mathrm{~Hz}, 1 \mathrm{H}, \mathrm{H}-23)$, 5.14 (dd, $J=15.3,8.4 \mathrm{~Hz}, 1 \mathrm{H}, \mathrm{H}-22), 3.97(\mathrm{~m}, 1 \mathrm{H}, \mathrm{H}-3), 1.00$ (d, $J=6.6 \mathrm{~Hz}, 3 \mathrm{H}, \mathrm{Me}-21), 0.91$ (d, $J=6.8 \mathrm{~Hz}$, $3 \mathrm{H}, \mathrm{Me}-28), 0.88$ (s, 3H, Me-19), 0.83 (d, $J=6.8 \mathrm{~Hz}, 3 \mathrm{H}, \mathrm{Me}-27$ ), 0.82 (overlap, $\mathrm{m}, 6 \mathrm{H}, \mathrm{Me}-18, \mathrm{Me}-26) .{ }^{13} \mathrm{C}$ $\operatorname{NMR}\left(151 \mathrm{MHz}, \mathrm{CDCl}_{3}\right.$ ) ठ 135.44 (s, C-6), 135.22 (s, C-22), 132.32 (s, C-23), 130.76 (s, C-7), 82.17 (s, C-5), 79.44 (s, C-8), 66.46 (s, C-3), 56.20 (s, C-17), 51.69 (s, C-14), 51.09 (s, C-9), 44.57 (s, C-13), 42.78 (s, C-24), 
39.74 (s, C-20), 39.35 (s, C-12), 36.97 (s, C-4), 36.93 (s, C-10), 34.70 (s, C-1), 33.07 (s, C-25), 30.11 (s, C-2), 28.65 (s, C-16), 23.40 (s, C-11), 20.88 (s, C-21), 20.63 (s, C-15), 19.95 (s, C-27), 19.65 (s, C-26), 18.18 (s, C$19), 17.56$ (s, C-28), 12.87 (s, C-18).

\subsection{In-vitro Insecticidal activity of isolated compounds}

After the isolation, purification and identification, compounds 1-10 were evaluated for the insecticidal activity against $B$. tabaci. The results of the mean mortality via both contact and stomach toxicity was exhibited from Figure 3 to figure 6 . Futhermore, the results of the $L_{50}$ value at $72 \mathrm{~h}$ were presented in Table 2. However, the detail data was placed in supplementary material as table S1 to Table S10.

According to the mortality results of compound $1,41.67 \%$ mortality was reported at $72 \mathrm{~h}$ and $50 \mathrm{ppm}$ via contact assay. Similarly, 38.33\% mortality was displayed at the same concentration and time exposure via stomach assay (Figure 3). Similar results for insecticidal activity was afforded by compound 2 by both bioassays i.e. 47.50 and $44.17 \%$ mortality was recorded at $50 \mathrm{ppm}$ via contact as well as stomach assay respectively (Figure 3). Results apparent from Figure 4 represents that compound 3 has higher mortality as 97.50 and $79.17 \%$ at 50 ppm with exposure of 72 and 48 h by stomach assay. Similarly, by contact toxicity assay 79.17 and $54.17 \%$ mortality was exerted at the same concentration and time. Moreover, significant mortality was also afforded at $25 \mathrm{ppm}$ by stomach as well as contact assay i.e. $80.83 ; 66.67 \%$ and $66.67 ; 46.67 \%$ mortality at 72 and $48 \mathrm{~h}$ respectively. Similar results for mortality were also displayed by compound 4, where, 100 and $85.00 \%$ mortality was reported at $50 \mathrm{ppm}$ at exposure of 72 and 48 h respectively. Similarly, $92.50,76.66$ and $66.67 \%$ mortality was displayed at 25, 12.5 and 6.5 ppm at $72 \mathrm{~h}$ respectively. However, via contact assay maximum $87.50 \%$ mortality was recorded at $72 \mathrm{~h}$ and $50 \mathrm{ppm}$ concentration (Figure 4). Results for insecticidal activity of compound $\mathbf{5}$ are presented in (Figure 5) which showed that 70.83 and $66.67 \%$ mortality was displayed at $72 \mathrm{~h}$ at the concentration of 50 and 25 ppm respectively by stomach toxicity assay. Similarly, by contact assay 53.33 and $50.83 \%$ mortality was recorded at the same concentration and time exposure respectively. Same trend of mortality was exerted by compound 6 where 41.67 and $36.67 \%$ mortality was recorded at $50 \mathrm{ppm}$ and time exposure of $72 \mathrm{~h}$ ((Figure 5)). Alternatively, compound 7 was the best compound that presented significantly high mortality i.e. 100 and $85.00 \%$ mortality via stomach assay at $50 \mathrm{ppm}$ concentration with $72 \mathrm{~h}$ exposure. Similarly, at $25 \mathrm{ppm} 92.50$ and $71.67 \%$ mortality was recorded at the same exposure period. Interestingly, this compound displayed $66.67 \%$ mortality ay $72 \mathrm{~h}$ exposure even at low concentration $(6.5 \mathrm{ppm})$. Whereas, relatively lower mortality i.e. 71.67 and $65.83 \%$ was recorded by contact assay at 50 and $25 \mathrm{ppm}$ and $72 \mathrm{~h}$ exposure respectively (Figure 5). Results presented in (Figure 6) for compound $\mathbf{8}$ described that maximum mortality was afforded at 50 and $25 \mathrm{ppm}$ with 72 and $48 \mathrm{~h}$ as 90.00 and $81.67 \%$ respectively by stomach toxicity assay, whereas, at the same concentration and exposure period 61.67 and $57.56 \%$ mortality was recorded by contact assay. Interestingly, compound 9 produced higher mortality on using contact assay rather than stomach assay like other described compounds. However, this compound produced moderate mortality in both bioassay methods i.e. 66.67; 51.67 and $64.17 ; 50.83$ at 50 ppm at 72 and $48 \mathrm{~h}$ exposure respectively (Figure 6). On the other hand, compound 10 recorded relatively higher mortality as 80.83 and $68.33 \%$ by contact toxicity assay at 50 
and $25 \mathrm{ppm}$ and $72 \mathrm{~h}$ exposure period respectively as compared to contact toxicity assay which afforded 56.67 and $46.83 \%$ mortality at the same concentration and exposure period.

In essence, compound $\mathbf{3}$ exhibited an extraordinary mortality against $B$. tabaci on both contact and stomach experiments. Compound $\mathbf{4}$ and $\mathbf{7}$ highlighted the significant insecticidal activities on stomach bioassay and strong insecticidal activities on contact bioassay while compound $\mathbf{5 , 8}$ and $\mathbf{1 0}$ demonstrated their strong stomach toxicity effectiveness while their contact insecitidal activities were moderate. Comparing to the values above, compounds 1, 2, 6 and 9 ranged from moderate to fair effectiveness to $B$. tabaci.

Table 2. Probit analysis of the effects of compounds $1-10$ on $B$. tabaci at $72 \mathrm{~h}$ 


\begin{tabular}{|c|c|c|c|c|c|c|}
\hline & \multirow[t]{2}{*}{ Compound } & \multirow[t]{2}{*}{$\mathrm{LC}_{50}$} & \multicolumn{2}{|c|}{95 \% F.L } & \multirow[t]{2}{*}{ Slope \pm SE } & \multirow[t]{2}{*}{$x^{2}$} \\
\hline & & & lower & upper & & \\
\hline \multirow{10}{*}{ contact } & 1 & $>50$ & 36.33 & 777.49 & $0.96 \pm 0.34$ & 0.42 \\
\hline & 2 & $>50$ & 40.42 & 265.48 & $0.99 \pm 0.21$ & 0.05 \\
\hline & 3 & 10.59 & 4.74 & 23.64 & $0.92 \pm 0.18$ & 1.02 \\
\hline & 4 & 19.05 & 13.74 & 26.40 & $0.88 \pm 0.07$ & 5.60 \\
\hline & 5 & $>50$ & 22.75 & 313.89 & $0.89 \pm 0.29$ & 2.03 \\
\hline & 6 & $>50$ & 22.83 & 3788.71 & $1.00 \pm 0.57$ & 0.01 \\
\hline & 7 & 26.59 & 16.80 & 42.07 & $0.96 \pm 0.10$ & 0.83 \\
\hline & 8 & $>50$ & 6.87 & 593.56 & $0.95 \pm 0.49$ & 0.18 \\
\hline & 9 & 41.52 & 20.34 & 84.76 & $0.99 \pm 0.16$ & 0.10 \\
\hline & 10 & $>50$ & 13.90 & 1548.93 & $0.92 \pm 0.53$ & 0.42 \\
\hline \multirow{10}{*}{ stomach } & 1 & $>50$ & 6.82 & 52764.85 & $0.95 \pm 0.99$ & 0.24 \\
\hline & 2 & $>50$ & 36.52 & 228.20 & $0.98 \pm 0.20$ & 0.72 \\
\hline & 3 & 11.42 & 8.51 & 15.34 & $0.99 \pm 0.07$ & 0.74 \\
\hline & 4 & 5.66 & 3.38 & 9.47 & $0.99 \pm 0.11$ & 0.37 \\
\hline & 5 & 22.29 & 12.35 & 40.24 & $0.99 \pm 0.13$ & 0.17 \\
\hline & 6 & $>50$ & 23.66 & 1704.02 & $0.98 \pm 0.47$ & 0.34 \\
\hline & 7 & 5.65 & 3.38 & 9.47 & $0.99 \pm 0.11$ & 0.36 \\
\hline & 8 & 13.83 & 10.32 & 18.53 & $0.99 \pm 0.06$ & 1.06 \\
\hline & 9 & $>50$ & 27.75 & 149.46 & $0.81 \pm 0.19$ & 3.30 \\
\hline & 10 & 22.06 & 16.36 & 29.74 & $0.97 \pm 0.07$ & 1.25 \\
\hline
\end{tabular}

F.L (Fiducial Limit); X2; (Chi-square); SE (Standard Error); LC 50 (Lethal Concentration)

Probability analysis showing the $\mathrm{LC}_{50}$ values, slope value, Chi-square and fiducial limits at $95 \%$ confidence limit. Lowest $\mathrm{LC}_{50}$ values displayed by compounds 3,4 and 7 as $11.42,5.66$ and $5.65 \mu \mathrm{g} / \mathrm{mL}$ and $10.59,19.05$ and $26.59 \mu \mathrm{g} / \mathrm{mL}$ respectively via stomach and contact assay which illustrates their extraordinary insecticidal activity against $B$. tabaci. Whereas, other compounds displayed higher $\mathrm{LC}_{50}$ values via stomach as well as contact assay respectively that showed their less toxicity (Table 2). 
Several problems are associated with the use of synthetic chemicals for pest management, the introduction of natural products for this purpose is the primary concern. Essential oils, extracts and biologically active compounds are commonly used due to their effectiveness and safety for the environment as well as human beings. Secondary metabolites or natural products isolated from botanical source and range of microorganisms displayed bioactivity such as insecticidal, microbial, fungicidal and cytotoxic properties and contribute to their survival in several ways ${ }^{30}$. However, in the current research study all isolated compounds were evaluated for their in-vitro insecticidal activity against Bemisia tabaci. Different compounds displayed variable insecticidal activities from excellent to moderate activity.

The toxicity results of spinasterol,22,23-dihydrospinasterol reported by Maqsood et al. are in accordance with the results that documented $\mathrm{LC}_{50}$ values of 32.36 and $44.49 \mu \mathrm{g} / \mathrm{mL}$ by contact as well as residual assay respectively against Brevicoryne brassicae ${ }^{10}$. R.M. Zolotar et al. screened out ecdysteroids and were evaluated for their insecticidal activity against the Colorado beetle (Leptinotarsa decemlineata) using contact feeding method, that showed significant activity for isolated compounds ${ }^{31}$. The isolation of appropriate sterol from the Beauveria sp. and its activity against $B$. tabaci are in accordance with the findings of R.M. Zolotar et al. Similar results on insecticidal activity of ergosterol peroxide isolated from Nomuraea rileyi against tobacco cutworm were documented by Pannipa Prompiboon et al. ${ }^{32}$ who reported the moderate effects such as $46.7 \%$ mortality was caused against Spodoptera litura larvae via topical application at an interval of one week with 90-120 $\mathrm{\mu g} /$ insect, whereas, our research results showed $38.33 \%$ mortality at $72 \mathrm{~h}$ exposure at concentration of $50 \mathrm{ppm}$ on B. tabaci. Additional biological activities of compounds ergosterol peroxide include antioxidant activities ${ }^{33}$, antimycobacterial activities 34 inflammatory activities ${ }^{35}$. Furthermore, the research study did not find any published material with the same compounds that was isolated on insecticidal activity study. That suggests there is still great potential of prospects on finding new active molecules from known entomopathogenic fungi.

B. tabaci is a potent agricultural pest with strong tendency to develop resistance against known pesticides, therefore new controlling agents are in constant need. In our study methyl 1,4-dihydro-4-oxo-2quinolinecarboxylate (4), bassiatin (3), 6-dehydrocerevisterol (7) have shown promising insecticidal activity against $B$. tabaci. Compounds 1, 2, 4-9 are discovered in Beauveria sp. for the first time and compound $\mathbf{4}$ was discovered in natural products for the first time. Compound $\mathbf{4}$ was previously synthesized by Mazzoni O. ${ }^{29}$, even this is a known compound, we still use 2D NMR to fix the structure, due to no ${ }^{13} \mathrm{C}$ NMR data was reported in literature.

Although different biological control approaches have been employed in current agriculture system to control pest on crops and vegetables, however, the use of fungal based biological compounds against $B$. tabaci is limited. The outcomes from this current study offered that isolated compounds from Beauveria sp. useful for the control of sucking pest especially $B$. tabaci. Hence, the introduction of these biologically active compounds could be an effective alternative and potential means to control such pests. 


\section{Materials And Methods}

\subsection{General Experimental Procedures}

NMR spectra were captured on an Avance-600 NMR spectrometer (Bruker, 57 Karlsruhe, Germany) at room temperature. High-resolution electrospray ionization mass spectrometry (HRESIMS) spectra data were recorded on a 6500 series quadrupole-time-of-flight (Q-TOF) mass spectrometer (Agilent, Santa Clara, CA). Mass spectrometry also recorded on LCMS 8050 (Shimadzu, Tokyo, Japan). Highperformance liquid chromatography (HPLC) analysis was performed on a 1260 Infinity LC system (Agilent, Santa Clara, CA), and the column used was a $250 \mathrm{~mm} \times 4.6 \mathrm{~mm}$ i.d., $5 \mu \mathrm{m}$, ZORBAX Eclipse XDB (Agilent, Santa Clara, CA). Semipreparative HPLC was performed on a 1260 series system (Agilent), and the column used was a $250 \mathrm{~mm} \times 9.4 \mathrm{~mm}$ i.d., $5 \mu \mathrm{m}$, ZORBAX Eclipse XDB (Agilent). Column chromatography was performed using silica gel (100-200 mesh) (Qingdao Ocean Chemical Co. Ltd., Qingdao, China) and Sephadex LH-20 (GE Healthcare, Uppsala, Sweden). All chemical reagents were purchased from a chemical reagent company (Sinopharm Chemical Reagent Co., Ltd., Shanghai, China) and used without further purification.

\subsection{Fermentation and Extraction of Beauveria sp. LY2}

The Beauveria sp. LY2 was obtained from the Laboratory of Microbial Metabolites, College of Plant Protection of Shenyang Agricultural University, China, which was cultured on SDAY medium at $25^{\circ} \mathrm{C}$ in an incubator. The fermentation has two stages where the first stage, SDY medium ( $1 \%$ peptone, $1 \%$ yeast extract, $4 \%$ glucose, $\mathrm{pH}=7.2$ ) was used. Put a $0.5 \mathrm{~cm}$ diameter fungi pancake with SDAY medium into a $250 \mathrm{~mL}$ Erlenmeyer flask which contains $40 \mathrm{~mL}$ of SDY medium, then incubated them at $25^{\circ} \mathrm{C}$ with 180 rpm shaking speed for 3 days as to prepare the seed culture. In the second stage, Czapek-Dox medium $\left(0.03 \% \mathrm{NaNO}_{3}, 0.01 \% \mathrm{~K}_{2} \mathrm{HPO}_{4} \cdot 3 \mathrm{H}_{2} \mathrm{O}, 0.005 \% \mathrm{MgSO}_{4} \cdot 7 \mathrm{H}_{2} \mathrm{O}, 0.005 \% \mathrm{KCl}, 0.0001 \% \mathrm{FeSO}_{4} \cdot 7 \mathrm{H}_{2} \mathrm{O}, 3 \%\right.$ sucrose, $\mathrm{pH}=7.0$ ) was used. $1202 \mathrm{~L}$ Erlenmeyer flasks, each contains $400 \mathrm{~mL}$ Czapek-Dox medium, were inoculated with $40 \mathrm{~mL}$ seed culture at $25^{\circ} \mathrm{C}$ with $180 \mathrm{rpm}$ shaking speed for 15 days. The fermentation cultures were centrifuged at $4{ }^{\circ} \mathrm{C}$ with $5000 \mathrm{rpm}$ for 30 mins to remove mycelia, then add 3 $\%$ Amberlite XAD 16 resin into the broth at $25^{\circ} \mathrm{C}$ with $180 \mathrm{rpm}$ shaking speed for 4 hours. Resin was collected by using 100 meshes gauze and extracted four times with methanol. The dried crude extract was harvested through reduced pressure concentration. The dried methanol extract was dissolved in 600 $\mathrm{mL}$ solution $\left(50 \% \mathrm{CH}_{3} \mathrm{OH}, 50 \% \mathrm{H}_{2} \mathrm{O}\right.$ ), the solution was extracted four times by $600 \mathrm{~mL} \mathrm{CH}_{2} \mathrm{Cl}_{2}$. Collecting the resulted extract $\mathrm{CH}_{2} \mathrm{Cl}_{2}$ solution then concentrate it to get $10.0 \mathrm{~g}$ solid brown residue.

\subsection{Isolation and Purification}

The concentrated extract was purified by using silica gel chromatography to elute stepwise with $\mathrm{CH}_{2} \mathrm{Cl}_{2}$ $\mathrm{MeOH}(100: 0,50: 1,25: 1,10: 1$ and 0:100, 1.5 L each) as the mobile phase to afford six fractions, A to G. C was separated via silica gel chromatography with PE:EA (9:1, 4:1, 7:3, 6:4 and 1:1, $300 \mathrm{~mL}$ each ) as the mobile phase to yield compound 3 (110 mg), compound $\mathbf{9} \otimes 7.3 \mathrm{mg} 囚$ and compound 10 (14.4 mg). Fraction 
E was subjected to gel chromatography on Sephadex $\mathrm{LH}-20$ eluted with $\mathrm{CH}_{2} \mathrm{Cl}_{2}-\mathrm{MeOH}$ (1:1) to obtain compound $\mathbf{5}$ (16.7 mg). D, F, G was purified by reverse-phase semi-preparative HPLC applying a $\mathrm{MeOH}-$ $\mathrm{H}_{2} \mathrm{O}$ gradient (contain $0.1 \% \mathrm{HCOOH}$ ) respectively. Compound $6(2 \mathrm{mg}$ ) was gained from $\mathrm{D}$ with $90 \%$ $\mathrm{MeOH}$ on $40 \mathrm{~min}$ (see Figure S26), compound $7(4 \mathrm{mg}$ ) and compound $8(4.2 \mathrm{mg}$ ) were also obtained from D with $85 \% \mathrm{MeOH}$ on $18 \mathrm{~min}$ and $20 \mathrm{~min}$ (see Figure S30 and Figure S34). Compound 4 (3.1 mg) was yielded from F with $77 \% \mathrm{MeOH}$ on $28 \mathrm{~min}$ (see Figure S19), 1 (3.8 mg) and 2 (25.9 mg) was obtained from $\mathrm{G}$ with conditions with $98 \% \mathrm{MeOH}$ on 10 min and 16 min respectively (see Figure $\mathrm{S} 7$ and Figure S12).

\subsection{Evaluation of Insecticidal Activity against B. tabaci}

\subsubsection{Bemisia tabaci Culture}

The whiteflies B-biotype B. tabaci (MEAM1) are from Liaoning Key Labortatory of Economic and Applied Entomology was cultured in a controlled greenhouse at $25-27{ }^{\circ} \mathrm{C}, 60 \%-70 \%$ relative humidity $(\mathrm{RH})$ with 16 : 8 (light: dark) photoperiod, on around 2 months old cotton plants, Gossypium hirsutum.

\subsubsection{Preexperiment Container Preparation}

One side of a lightproof bi-pass glass tube ( $3 \mathrm{~cm}$ inside diameter and $6 \mathrm{~cm}$ height) was covered with a stretched Parafilm M membrane (the first layer). Another side sealed with one piece of 100 meshes gauze and a rubber band ${ }^{36}$. All items had to be completely sterile.

\subsubsection{Experiment of Stomach Insecticidal Activity to B. tabaci}

The whitefly diet comprised of $30 \%$ (w / v) sucrose with serial dilutions of each compound $(50,25,12.5$, $6.25 \mu \mathrm{g} / \mathrm{mL}$ respectively), each diet contained $0.5 \%$ Tween 80 and $0.002 \%$ DMSO. Diet aliquots (200

$\mu \mathrm{L}$ ) containing compounds were dispensed on top of the first layer of stretched Parafilm membrane over each container; another stretched Parafilm membrane was placed over the diet aliquots to prevent evaporation. 30 adults ( $2-5 \mathrm{~d}$ old) were aspirated from $G$. hirsutum into the container. Test containers were placed in a controlled greenhouse at $25-27{ }^{\circ} \mathrm{C}, 60 \%-70 \%$ under $16: 8$ (light : dark) photoperiod and mortality was recorded at 24,48 and $72 \mathrm{~h}$. Each iteration of the experiment consisted of four replicates for each concentration of each compound (4 replicates $\times 4$ concentrations $\times 3$ repetitions $\times 30$ whiteflies per tube $=1440 \mathrm{~B}$. tabaci per test compound).

\subsubsection{Experiment of Contact Insecticidal Activity to B. tabaci}

Used mixed solvent (methanol: dichloromethane $=1: 1$ ) to diluent each compound into serial concentrations $(50,25,12.5,6.25 \mu \mathrm{g} / \mathrm{mL}$ respectively), mixed solvent with compounds aliquots were dispensed into the container tube, rotated the tube once to let the solvent equally distributed and evaporate. 30 adults ( $2-5 \mathrm{~d}$ old) were aspirated from $G$. hirsutum into the container. Test containers were put in the controlled greenhouse at $25-27^{\circ} \mathrm{C}, 60-70 \%$ under $16: 8$ (light : dark) photoperiod. B. tabaci mortality was recorded at 24, 48 and $72 \mathrm{~h}$. Each iteration of the experiment consisted of four replicates 
for each concentration of the each compound (4 replicates $\times 4$ concentrations $\times 3$ repetitions $\times 30$ individual per tube $=1440 \mathrm{~B}$. tabaci per test compound).

\subsection{Statistical Analysis}

All the calculated data on mortality was analyzed by one way analysis of variance (ANOVA), the mean difference between treatments was envisioned for significance test by Duncan multiple range test DMRT with IBM-SPSS statistics 25.0 version software. Probit analysis was performed using EPA Probit analysis program version 1.5. 0 .

\subsection{Figure software}

All the chemical structures including bold bonds and arrows were drawn with ChemDraw 19.0. The Figures 3-6 were drawn with Origin 2019b (9.65).

\section{Conclusions}

The present research study indicated that the secondary metabolites from Beauveria sp. possess potential botanical agents. Results also demonstrated that $B$. tabaci produced significant sensitivity to isolated bassiatin (3) via both stomach and contact bioassay as well as methyl 1,4-dihydro-4-oxo-2quinolinecarboxylate (4) and 6-dehydrocerevisterol (7) via stomach bioassay. cerevisterol (5), (22E,24R)-

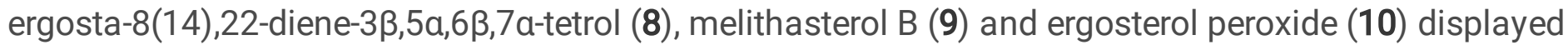
moderate toxicity against this pest. In contrast, cerebrosides $F(1)$ and cerebrosides B (2) showed much lower mortality than other compounds. Therefore, except compound $\mathbf{1}$ and $\mathbf{2}$, these compounds were introduced as alternatives to synthetic chemical insecticides. However, more research on the purification and characterization of bioactive compounds from entomopathogenic fungi is needed to be compared against $B$. tabaci and other agricultural insect pests in the future.

\section{Declarations}

Author Contributions: Conceptualization, R.A. and M.A.; methodology, R.A.; software, M.A.; validation, H.L., Y.W. and A.Z.; formal analysis, R.A. and M.A.; investigation, Y.B.; resources, Y.W.; writing-original draft preparation, R.A. and M.A.; writing-review and editing, Z.Y.; supervision, Y.B. and Z.Y.

Funding: This research was funded by National Key Research \& Development Program of China (2018YFD0800401).

Acknowledgments: We are grateful to Dr. David Hands of Lancaster University, UK for proofreading the manuscript. We are grateful to Dr. Junbo Luan of the Liaoning Key Laboratory of Economic and Applied Entomology as well as Dr. Xiaofeng Zhu of the Nematology Institute of Northern China, Shenyang Agricultural University, for providing whitefly and controlled greenhouse respectively.

Conflicts of Interest: The authors declare no conflict of interests. 


\section{References}

1. 100 of the World's Worst Invasive Alien Species. GLOBAL INVASIVE SPECIES DATABASE http://www.iucngisd.org/gisd/species.php?sc=106.

2. Brown, J. K., Frohlich, D. R. \& Rosell, R. C. The Sweetpotato or Silverleaf Whiteflies: Biotypes of Bemisia tabaci or a Species Complex? Annu. Rev. Entomol. 40, 511-534 (1995).

3. Tiwari, S. P., Nema, S. \& Khare, M. N. Whitefly- A Strong Transmitter of Plant Viruses. Int. J. Phytopathol. 2, 102-120 (2013).

4. Hopkinson, J. et al. Insecticide resistance status of Bemisia tabaci MEAM1 (Hemiptera: Aleyrodidae) in Australian cotton production valleys. Austral Entomology 59, 202-214 (2020).

5. Topçu, I., Karaca, M. M. \& Karut, K. Dominance of Bemisia tabaci MEAM1 species over MED (Hemiptera: Aleyrodidae) in greenhouse vegetables in Mersin, Turkey. Phytoparasitica 48, 159-166 (2020).

6. Ahmed, M. Z. et al. Host suitability comparison between the MEAM1 and Asiall 1 cryptic species of Bemisia tabaci in cotton-growing zones of Pakistan: Host suitability for $B$. tabaci species in cottongrowing zones of Pakistan. Pest. Manag. Sci. 70, 1531-1537 (2014).

7. Shah, R., Al-Sadi, A. M., Scott, I. M., AlRaeesi, A. \& AlJahdhami, A. A. Insecticide resistance monitoring in whitefly (Bemisia tabaci) (Hemiptera: Aleyrodidae) in Oman. Journal of Asia-Pacific Entomology 23, 1248-1254 (2020).

8. Tilman, D. Global environmental impacts of agricultural expansion: The need for sustainable and efficient practices. Proceedings of the National Academy of Sciences 96, 5995-6000 (1999).

9. Devi, R. et al. Fungal secondary metabolites and their biotechnological applications for human health. in New and Future Developments in Microbial Biotechnology and Bioengineering 147-161 (Elsevier, 2020). doi:10.1016/B978-0-12-820528-0.00010-7.

10. Ahmed, M. et al. Spinasterol, 22,23-Dihydrospinasterol and Fernenol from Citrullus Colocynthis L. with Aphicidal Activity against Cabbage Aphid Brevicoryne Brassicae L. Molecules 25, 2184 (2020).

11. Dannon, H. F. et al. Toward the efficient use of Beauveria bassiana in integrated cotton insect pest management. J Cotton Res 3, 24 (2020).

12. Amin, G. A., Youssef, N. A., Bazaid, S. \& Saleh, W. D. Assessment of insecticidal activity of red pigment produced by the fungus Beauveria bassiana. World J Microbiol Biotechnol 26, 2263-2268 (2010).

13. $\mathrm{Xu}, \mathrm{Y}$. et al. Biosynthesis of the cyclooligomer depsipeptide bassianolide, an insecticidal virulence factor of Beauveria bassiana. Fungal Genetics and Biology 46, 353-364 (2009).

14. Scherkenbeck, J., Jeschke, P. \& Harder, A. PF1022A and Related Cyclodepsipeptides - A Novel Class of Anthelmintics. CTMC 2, 759-777 (2002).

15. Mallebrera, B., Prosperini, A., Font, G. \& Ruiz, M. J. In vitro mechanisms of Beauvericin toxicity: A review. Food and Chemical Toxicology 111, 537-545 (2018). 
16. Brewer, D., Jen, W.-C., Jones, G. A. \& Taylor, A. The antibacterial activity of some naturally occurring 2,5-dihydroxy-l,4-benzoquinones. Can. J. Microbiol. 30, 1068-1072 (1984).

17. Fan, Y. et al. Regulatory cascade and biological activity of Beauveria bassiana oosporein that limits bacterial growth after host death. Proc Natl Acad Sci USA 114, E1578-E1586 (2017).

18. Terry, B. J. et al. Inhibition of herpes simplex virus type 1 DNA polymerase by the natural product oosporein. J. Antibiot. 45, 286-288 (1992).

19. Wang, Q. \& Xu, L. Beauvericin, a Bioactive Compound Produced by Fungi: A Short Review. Molecules 17, 2367-2377 (2012).

20. Cheng, S.-Y. et al. Ceramide and Cerebrosides from the Octocoral Sarcophyton ehrenbergi ${ }^{\#}$. J. Nat. Prod. 72, 465-468 (2009).

21. Kagamizono, T. et al. Bassiatin, a New Platelet Aggregation Inhibitor Produced by Beauveria bassiana K-717. J. Antibiot. 48, 1407-1413 (1995).

22. Mazzoni, O. et al. Synthesis and Pharmacological Evaluation of Some 4-0xo-quinoline-2-carboxylic Acid Derivatives as Anti-inflammatory and Analgesic Agents. Arch. Pharm. Pharm. Med. Chem. 343, 561-569 (2010).

23. Guillou, S. \& Janin, Y. L. Optimized palladium-based approaches to analogues of PK 11195. Journal of Heterocyclic Chemistry 45, 1377-1384 (2008).

24. New Steryl Esters of Fatty Acids from the Mangrove Fungus Aspergillus awamori. Helvetica Chimica Acta 90, 14 (2007).

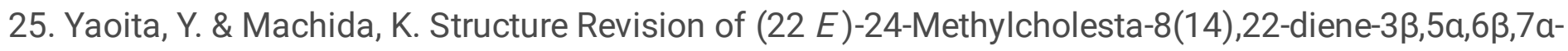
tetraol from the Marine-Derived Fungus Penicillium sp. Natural Product Communications 11, $1934578 \times 1601100$ (2016).

26. Fangkrathok, N., Sripanidkulchai, B., Umehara, K. \& Noguchi, H. Bioactive ergostanoids and a new polyhydroxyoctane from Lentinus polychrous mycelia and their inhibitory effects on E2-enhanced cell proliferation of T47D cells. Natural Product Research 27, 1611-1619 (2013).

27. Sun, Y., Tian, L., Huang, J., Li, W. \& Pei, Y. Cytotoxic sterols from marine-derived fungus Pennicillium sp. Natural Product Research 20, 381-384 (2006).

28. Youssef, D. T. A., Badr, J. M., Shaala, L. A., Mohamed, G. A. \& Bamanie, F. H. Ehrenasterol and biemnic acid; new bioactive compounds from the Red Sea sponge Biemna ehrenbergi. Phytochemistry Letters 12, 296-301 (2015).

29. Mazzoni, O. et al. Synthesis and Pharmacological Evaluation of Some 4-0xo-quinoline-2-carboxylic Acid Derivatives as Anti-inflammatory and Analgesic Agents. Arch. Pharm. Pharm. Med. Chem. 343, 561-569 (2010).

30. Xiao, J. et al. Secondary Metabolites from the Endophytic Botryosphaeria dothidea of Melia azedarach and Their Antifungal, Antibacterial, Antioxidant, and Cytotoxic Activities. J. Agric. Food Chem. 62, 3584-3590 (2014). 
31. Zolotar, R. M., Bykhovets, A. I., Sokolov, S. N. \& Kovganko, N. V. STRUCTURE-ACTIVITY RELATIONSHIP OF INSECTICIDAL STEROIDS. IV. 3ß-CHLOROSUBSTITUTED DERIVATIVES OF CHOLESTEROL AND $\beta$-SITOSTEROL. 4.

32. Prompiboon, P., Bhumiratana, A., Ruchirawat, S., Boucias, D. G. \& Wiwat, C. Isolation of ergosterol peroxide from Nomuraea rileyi infected larvae of tobacco cutworm. World J Microbiol Biotechnol 24, 2909-2917 (2008).

33. Kim, S., Park, S., Min, T. \& Yu, K. Antioxidant activity of ergosterol peroxide (5,8-epidioxy-5. Chemical Society 819-823 (1999).

34. Duarte, N., Ferreira, M.-J. U., Martins, M., Viveiros, M. \& Amaral, L. Antibacterial activity of ergosterol peroxide against Mycobacterium tuberculosis: dependence upon system and medium employed. Phytotherapy Research 21, 601-604 (2007).

35. Akihisa, T. et al. Anti-Inflammatory and Anti-Tumor-Promoting Effects of Triterpene Acids and Sterols from the Fungus Ganoderma lucidum. Chemistry \& Biodiversity 4, 224-231 (2007).

36. GUO Jingjing, SHI Xueyan, \& GAO Xiwu. The rapid detection method for resistance to five neonicotinoid insecticides and sulfoxaflor in Myzus persicae. Chinese Journal of Pesticide Science 19, 555-562 (2017).

\section{Figures}




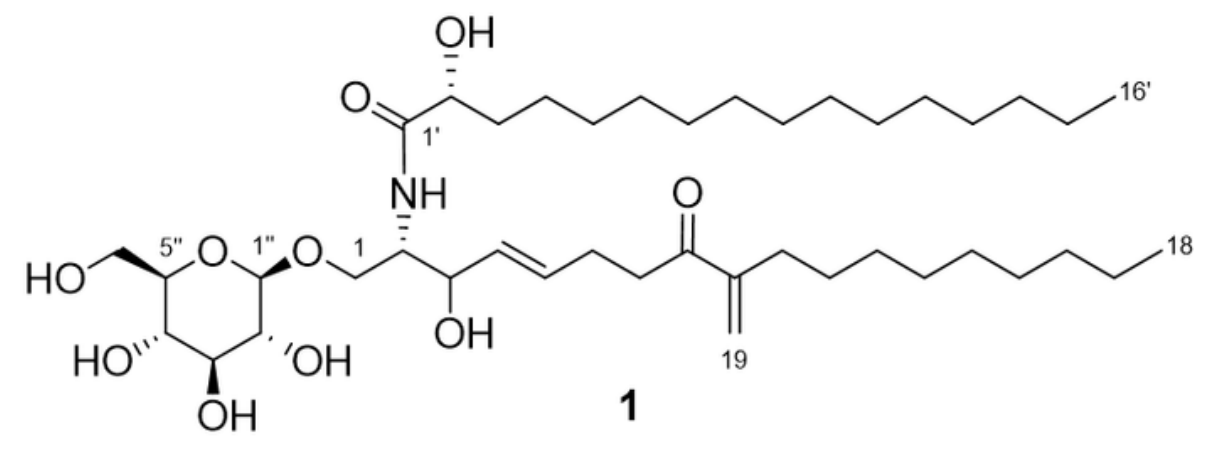<smiles>[1H]N1C(=O)[C@@H](C(C)C)OC(=O)[C@@H]1Cc1ccccc1</smiles>

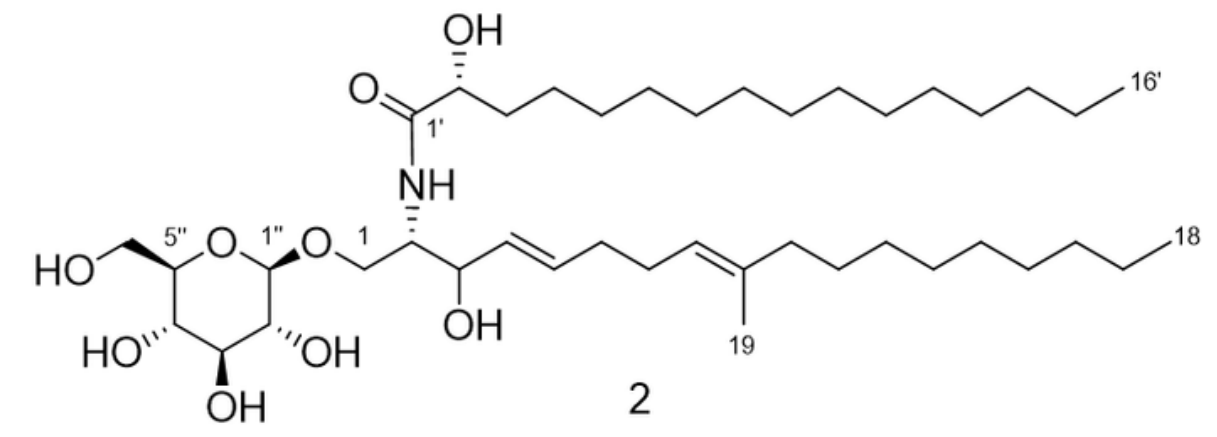<smiles>COC(=O)c1cc(=O)c2ccccc2[nH]1</smiles>

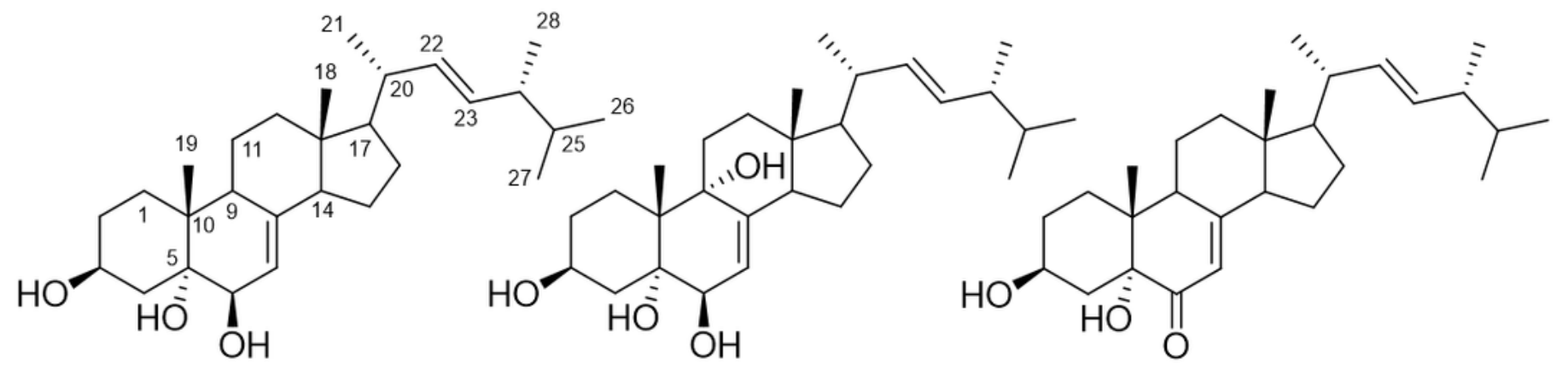

5

6

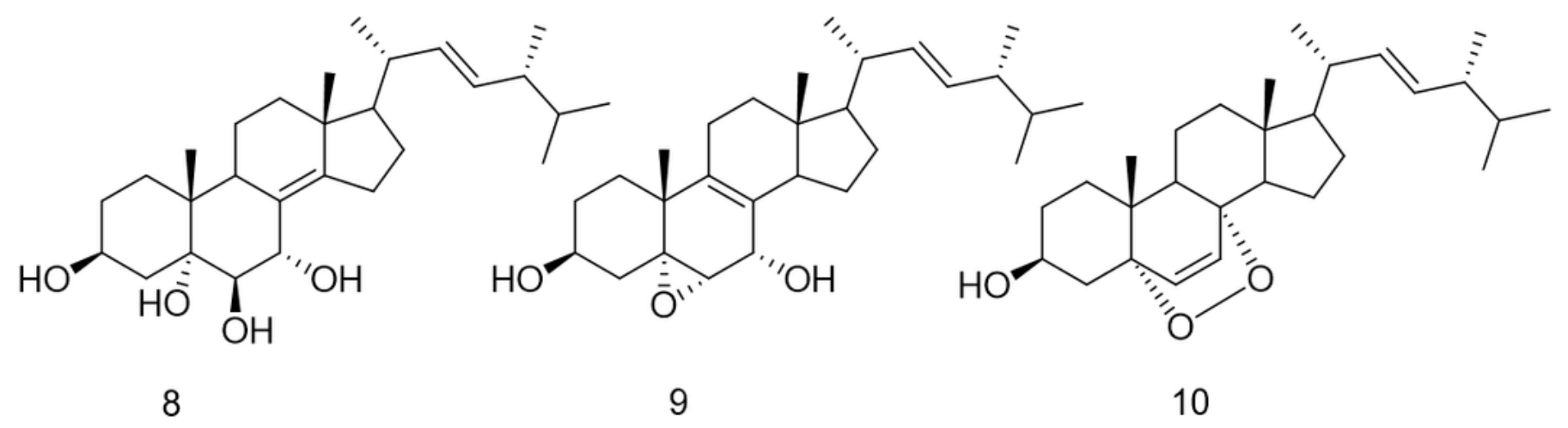

Figure 1

The chemical structures of the compounds 1-10 


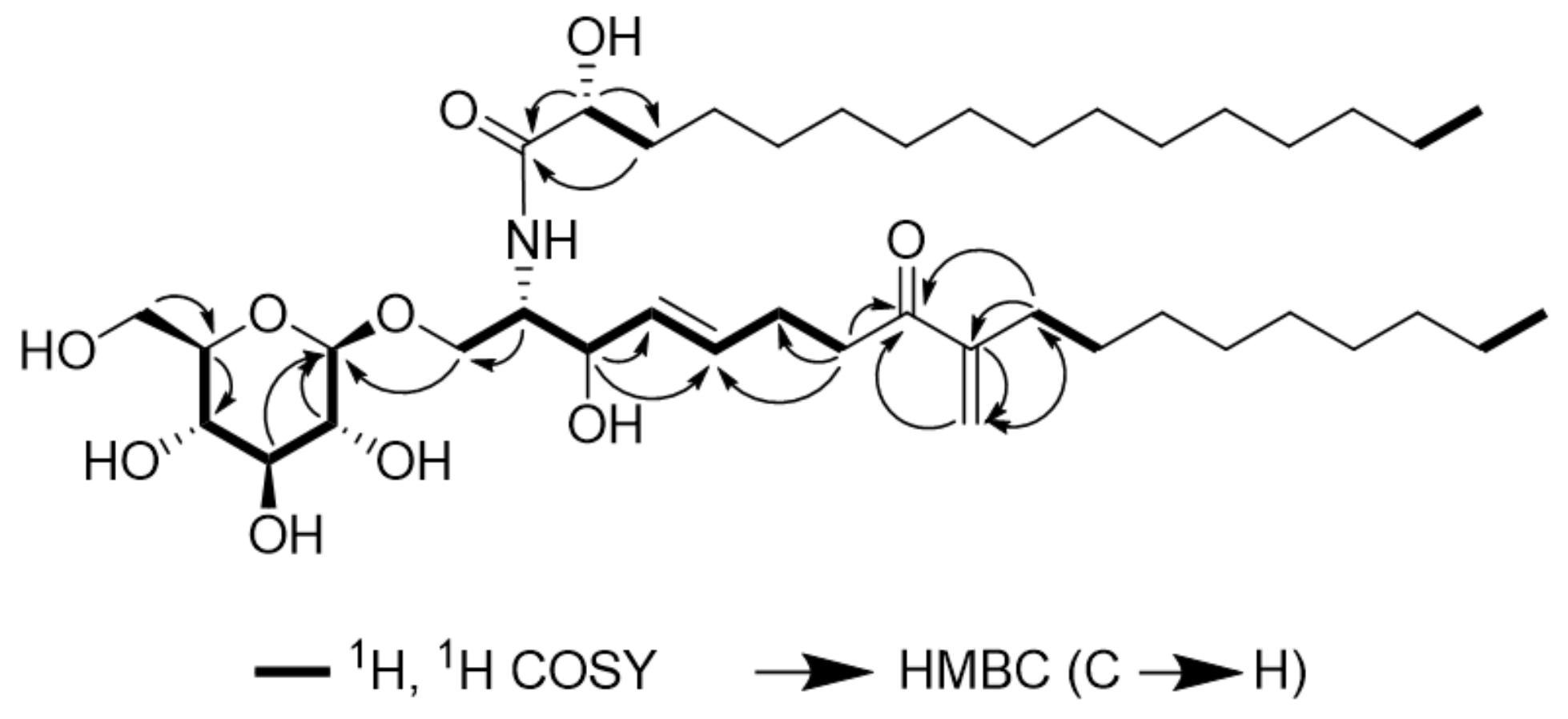

Figure 2

The key COSYヌbold囚and HMBC (arrows) correlations of compound 1
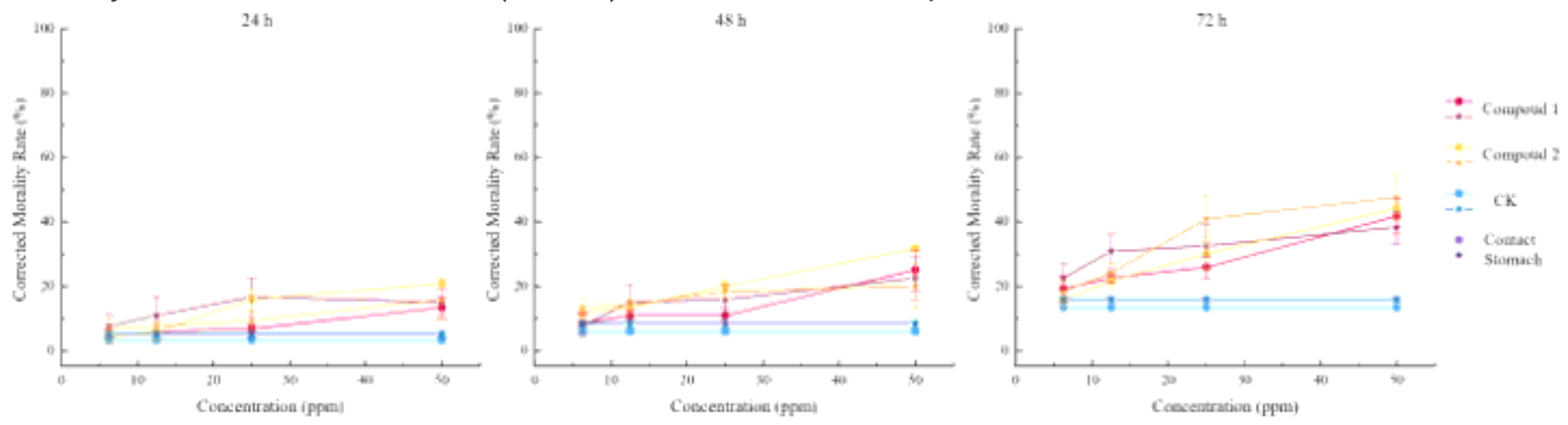

Figure 3

The mean morality rate of compound 1 and 2 with different concentrations at $24 \mathrm{~h}, 48 \mathrm{~h}$ and $72 \mathrm{~h}$.
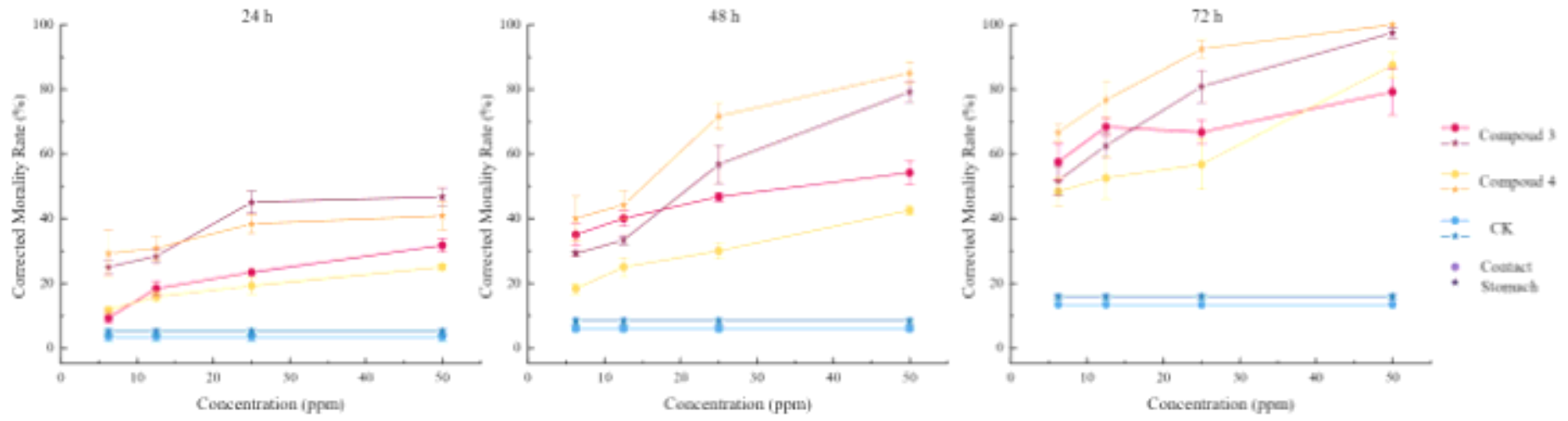

Figure 4 
The mean morality rate of compound 3 and 4 with different concentrations at $24 \mathrm{~h}, 48 \mathrm{~h}$ and $72 \mathrm{~h}$.
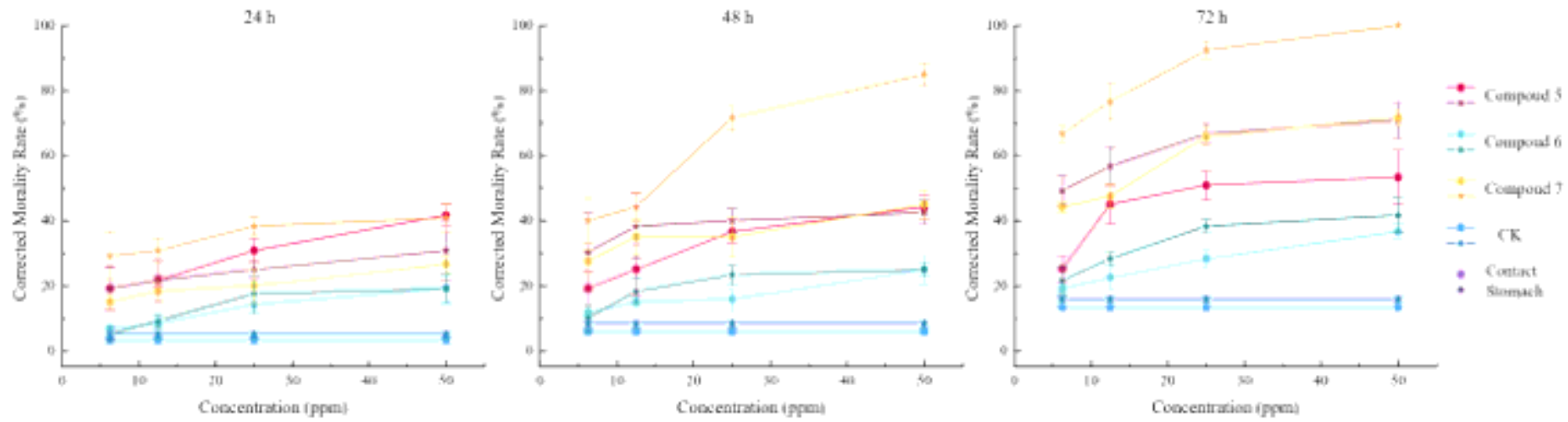

Figure 5

The mean morality rate of compound 5, 6 and 7 with different concentrations at $24 \mathrm{~h}, 48 \mathrm{~h}$ and $72 \mathrm{~h}$.
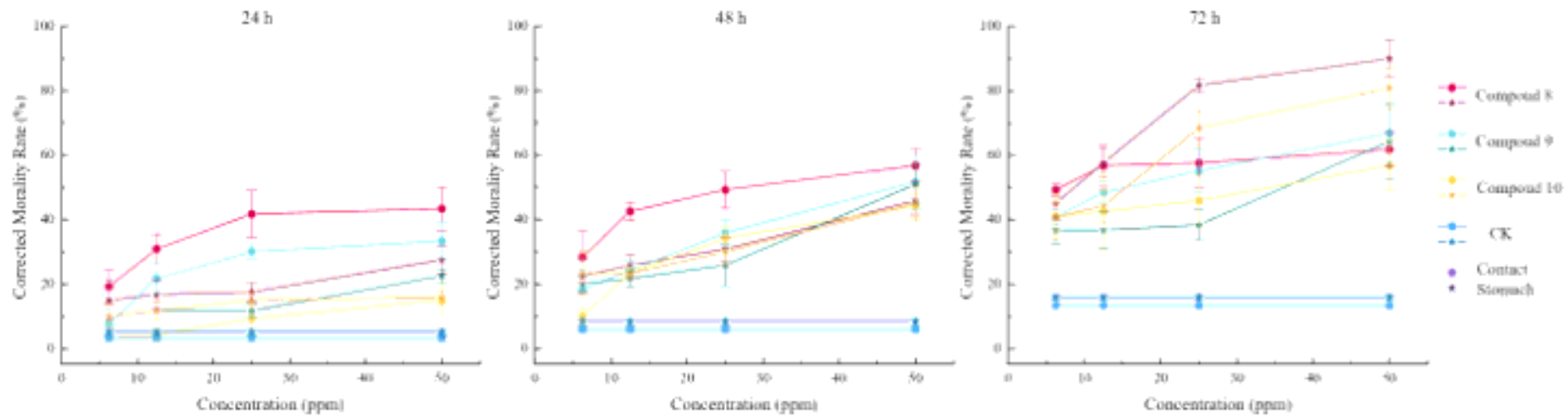

Figure 6

The mean morality rate of compound 8,9 and 10 with different concentrations at $24 \mathrm{~h}, 48 \mathrm{~h}$ and $72 \mathrm{~h}$.

\section{Supplementary Files}

This is a list of supplementary files associated with this preprint. Click to download.

- SupplementaryMaterialSR.docx 